\title{
Translocating Crocodiles
}

\author{
A.M. Morgan-Davies
}

The state of Borno, in Nigeria, is trying to increase its dwindling crocodile populations. In 1976 the State wildlife authorities confiscated fifteen crocodiles that were being illegally kept, and used them to augment a low population in a game reserve. This proved successful, and in 1979 they followed it with another successful translocation, this time of 20 crocodiles born and bred in Kyarimi Park Zoo of which the author was Curator. The latest news is that a third translocation is planned from a record batch of 112 bred in the Kyarimi Park Zoo.

On the south-western edge of Lake Chad in north-eastern Nigeria lies the small isolated fishing village of Baga. As recently as 1970 the village was on the lake shore, but the lake has receded so that it is now ten sandy kilometres away. Inland of Baga the general vegetation is sahel savanna, and although as recently as fifteen years ago it held large numbers of red-fronted gazelle Gazella rufifrons hasleri and ostrich Struthio camelus and, to a lesser extent, dama gazelle Gazella dama dama and Senegal hartebeest Damaliscus korrigum, the chances of seeing the first two species are poor, and the last two are now extinct. Among the dense papyrus cover on the lake shore the situation is no better. Sitatunga Limnotragus spekii and hippo Hippopotamus amphibius are rare, and the bushcow Syncerus nanus is extinct. The future of the isolated population of about 200 elephants Loxodonta africana that live an almost aquatic and restricted life in this area is similarly bleak.

However, it is not only the protein-producing animals that are in grave danger of extermination, but also the few remaining Nile crocodiles Crocodylus niloticus on the shores of Lake Chad. Each year a number are caught in fishing nets and, if too large to be subdued, dispatched for the value of their skins. Those that are small and controllable are taken home or sold. Many are kept by the richer families in any available space within their homes as a status symbol or object of curiosity, or even as a long-term gilt-edge investment, to be sold when they become too large, too dangerous and too costly to feed, or when ready cash is required. Some are sent south, where crocodiles are revered by some people and eaten by others.

In 1976, after months of investigation, a number of these owners of captive crocodiles were prosecuted and fined and their animals confiscated. Immediately after the court judgment and before the owners could dispose of their animals, staff of the Kyarimi Park Zoo moved in and removed 15 crocodiles averaging two metres in length. The confiscated animals were loaded and trucked $200 \mathrm{~km}$ south to Maiduguri, where they were kept for over a year. They were well fed and several were exposed to fresh air and sunlight for the first time in many years. As the Park already had a breeding collection of Nile crocodiles, it was decided to release the new animals in a suitable protected area, and they were moved by road to the Gashaka Game Reserve in Gongola State.

On the evening of December 191977 the 15 crocodiles, by now up to $2.5 \mathrm{~m}$ long, were placed in a specially designed transport cage built into a Mercedes 


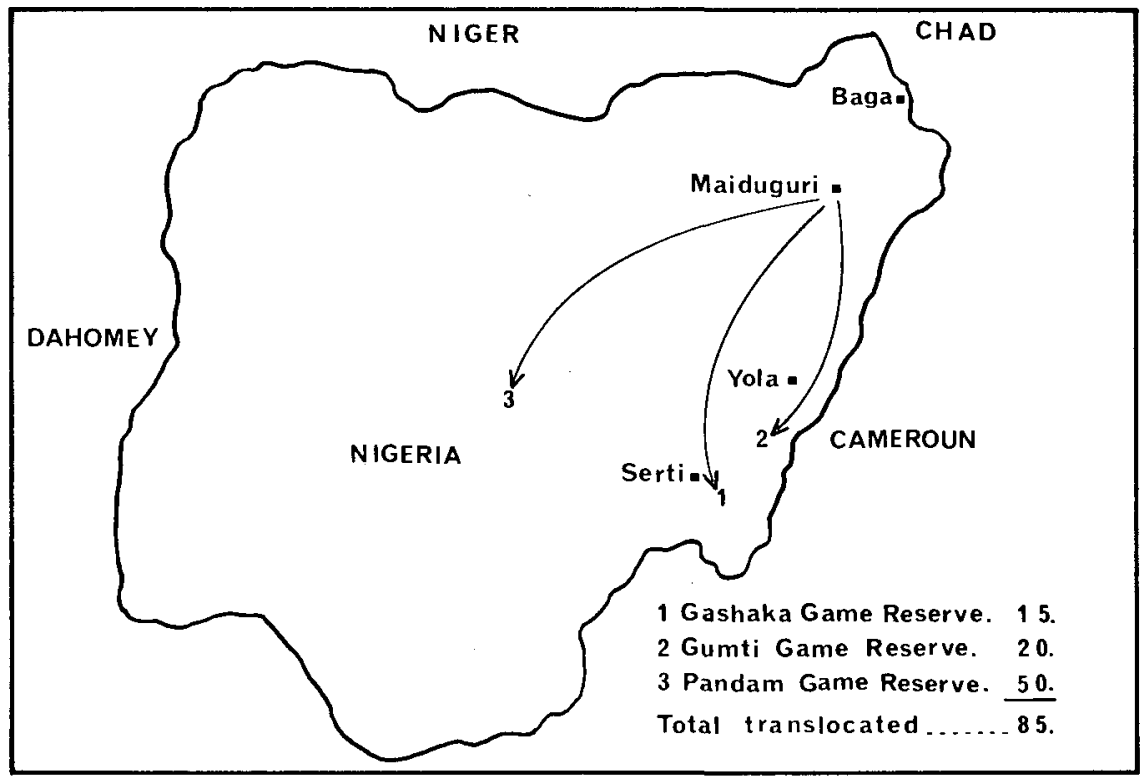

Unimog lorry, and before dawn next morning started the two-day journey south, arriving at Serti, the entrance to the Gashaka Game Reserve, at 4pm next day. Before dark, seven were released into the almost crystal-clear waters of the Kam river, tired but none the worse for their $800-\mathrm{km}$ journey. Next morning, after being enthusiastically welcomed by the local elders, the remaining eight were released in the Ngabo river, a tributary of the Kam, and further into the reserve. For the next week they were closely watched by the writer, and in the following months were often seen by Richard Barnwell, the wildlife ecologist, and his rangers.

In most of the rivers of the Gashaka Game Reserve there are large numbers of perch Lates niloticus, tiger fish Hydrocyon sp., and many species of Clarias and Barbus. Provided the reserve continues to receive full protection, its isolated location and ideal habitat make it very suitable for this first crocodile translocation exercise.

Encouraged by the success of this first operation, plans were made in 1978 to translocate a second batch of crocodiles, on this occasion animals bred and raised in the Kyarimi Park Zoo. In 1977, a year after major alterations to the design, size and landscaping of the old Nile crocodile enclosure, 36 young had been successfully hatched. To avoid accidents they were removed within ten hours of hatching to a nursery enclosure, where they remained for a year on a carefully prepared and administered diet and under the most hygienic conditions possible. For their second year they were moved to a much larger and less 'clinical' enclosure, and their diet altered. By the time they were two years old they were considered large and strong enough to fend for themselves in a natural environment, and, to make this transition less of a risk as far as feeding was concerned, their diet for the last four months of captivity was slowly changed to include live Tilapia and Clarias that they had to catch for themselves.

In April 1979, 20 of the largest were loaded into specially designed transport crates, each containing four animals, for the second translocation exercise. Because of their relatively small size, between $0.75 \mathrm{~m}$ and $1.0 \mathrm{~m}$ long, it was decided to release them in the shallow headwaters of a tributary of the Yim 
NILE CROCODILES born in the Kyarimi Park Zoo and released in the Gashaka Game Reserve

river, which traverses the Gumti Game Reserve, also in Gongola State. This would greatly reduce the danger of any of these smaller animals being washed down into the main waters of the Yim before they had 'acclimatised' themselves to the rigours of their new natural environment. After nearly two days on the road, mostly on rough, undulating dirt tracks through heavy Guinea savanna, the 20 crocodiles were finally released into Mbelagenagge, a secluded three-hectare lake that is the headwaters of a small stream that flows for about $10 \mathrm{~km}$ through heavy gallery forest before it reaches the Yim. The abundance of feed, the isolated location of the lake, and the fact that its outlet to the Yim river is not liable to major seasonal flash floods make it an excellent refuge for young crocodiles until they are old enough to enter the main flow of the Yim of their own accord.

In 1978 the Kyarimi Park Zoo produced a record batch of 112 young Nile crocodiles. These are being cared for in the same way, and plans have been finalised to translocate at least 50 to the Pandam Game Reserve in Plateau State, central Nigeria, in mid 1980 . Of the rest, 10-20 will be retained by the Kyarimi Park Zoo to increase for the long term the existing breeding nucleus of three males and eight females. Offers for stocking lakes and other suitable protected areas have been sent to all State Wildlife Sections of Nigeria and consideration is also being given to the feasibility of commercial crocodile farming by the Kyarimi Park Zoo, as is being done so successfully by the Samut Prakan Crocodile Farm in Thailand, the Natal parks in South Africa and others.

The long-term possibilities in the conservation and management of the crocodile at the Kyarimi Park Zoo are encouraging, and the Ministry of Animal and Forest Resources of Borno State are gratified that they can play a part in counteracting, to some extent, the deterioration in the status of the Nile crocodile.

\section{Acknowledgments}

I would like to express my appreciation to Mr Mari Madu, Permanent Secretary of the Ministry of Animal and Forest Resources, Borno State, Nigeria, for his constant support and interest in the conservation work of the Kyarimi Park Zoo. Also my gratitude to Mr Richard Barnwell, Ecologist of the Gongola State Wildlife Section, and to Mr Aliyu Ngulde and Mr Joseph Jack Lau of the Kyarimi Park Zoo, without whose help our breeding and translocation efforts would not have been a success.

Until 1979 A.M. Morgan-Davies was Curator of Kyarimi Park Zoo. 